\title{
MJN \\ STUDY OF ADVERSE PREGNANCY OUTCOMES AMONG FEMALE HEALTHCARE WORKERS IN KUCHING, SARAWAK
}

\author{
Gregory Xavier ${ }^{1 *}$, Anselm Su Ting ${ }^{1}$, Teh Jo Hun² \\ ${ }^{1}$ Faculty of Medical and Health Sciences University Malaysia Sarawak, Malaysia \\ ${ }^{2}$ Sibu Divisional Health Office, Malaysia \\ *Corresponding Author 's Email:gregshc@yahoo.co.uk
}

\begin{abstract}
Background: Working in the healthcare industry has its effects on the female workers fecundity. Disorders of reproduction is listed as one of the top ten leading work-related diseases and injuries. The objective of this study is to observe the occurrences of adverse pregnancy outcomes among female healthcare workers in relation to their work schedules and identify the most frequent adverse pregnancy outcome. Methods: A cross-sectional study was carried out obtaining pregnancy history and work schedule in the past three years. In the present study 469 respondents were obtained; 339 healthcare and 130 non-healthcare workers reporting a total of 564 pregnancies. Results: In this study, adverse pregnancy outcomes among female healthcare workers is significantly higher than non-healthcare workers. There is no significant findings between healthcare and non-healthcare workers with respect to the types of adverse pregnancy outcomes and the work schedule. However, from the respondents' lifetime pregnancy outcome, it is found that complete miscarriage occurred most frequently at $26.7 \%$ and among healthcare workers who work on shift. Conclusion: Healthcare workers carry a higher risk to experience adverse pregnancy outcome with complete miscarriage being the most common and most of these experiences occurs among those who work on shift/on-call.
\end{abstract}

Keywords: Adverse pregnancy outcomes, Healthcare, Female workers, Sarawak

\section{INTRODUCTION}

Pregnancy is a natural phenomenon and process which ensures the continuation of the human species. Hence, females are given more health considerations and care, with tailored, and some specific, programs just to ensure their good health. The occupational health regulations do have sections concerning the safety of pregnant women. But it is not as extensive and tailored specifically for women. Nevertheless, the number of women entering the workforce is increasing in all sectors (Burdorf et al., 2006). This is due to improved educational levels and development for women, making them more independent and in carrying out roles, duties, jobs usually reserved by men. Women are now, are just as exposed to the hazards in working environment as men (Figà-Talamanca, 2006). These hazards poses a risk into their fecundity. Stressors from the working environment have effects on their reproductive capability.

The National Institute for Occupational Safety and Health (NIOSH) lists disorders of reproduction as one of the top ten leading work-related diseases and injuries (Figà-Talamanca, 2006; Yamada, 1986; CDC, 1989). However, currently there is no surveillance for such disorders of reproduction in Malaysia. The types of disorders of reproduction classified, is not specified under NIOSH. However, the common ones reported in literature are; complete miscarriage, threatened miscarriage, prematurity, low birth weight and hypertensive disorders in pregnancy (CDC, 1989).

Healthcare is considered as one of the professions that is highly stressful due to its work nature. It carries a large responsibility simply because it deals with human lives hence it is attempted to ensure that there is close to no margin of error (Familoni, 2008). In addition, the 
long and odd working hours also contributes to the stress. The majority of healthcare workers are females as the large nursing section is dominated by them. This paper is to study the effects of working hours in relation to pregnancy outcomes experienced by the female healthcare staff in comparison to non-healthcare staff.

In general, the work schedule of healthcare workers in Malaysia is divided into 3 systems. One is the on-call system usually practiced by medical officers who actively work on station. The typical on-call working hours totals up to 32 hours straight. The number of times per week or month of on-call done depends on the needs of the particular department. It is common to find staff working on more than two on-calls per week. This brings the total number of working hours per week more than the stipulated 48 hours (Malaysia Employment Act, 1955). This practice is not deliberate but is a need based on the workload and demands to ensure an effective functioning healthcare delivery.

The second system is the shift system. In this system, the staff rotates their schedule between three shifts. The morning and evening shift are 7 hours and the night shift is 10 hours. These shift systems are usually carried out by the support staff including nurses. They normally would get a day or two off keeping with the 48 hours per week regulation. Following this normal rotation on average, the staff would work 45 hours per week. This rotational order is also found being practiced in the United Kingdom (Ball et al., 2014). The normal working hours or also called office hours is over 8 hours. This is usually practiced by health administrators, allied health and other auxiliary medical staff. These group of staff work 5 days a week from Monday to Friday with the weekends off. They work a total of 45 hours a week.

The objective of this study is to observe the occurrences of adverse pregnancy outcomes among female healthcare workers in relation to their work schedules in Kuching, Sarawak and identify the most frequent adverse pregnancy outcome.

\section{METHODOLOGY}

A cross-sectional study was carried out. The questionnaire elicits information of the respondents' demography, history of each pregnancy experienced and their concurrent work history for the past three years. The pregnancy history includes all pregnancies up to the age of 35 . Hence, the respondent's maximum age includes those up to the age of 38 , for their pregnancy if at the age of 35 years is accounted. In addition, the most frequent adverse pregnancy outcome experienced is denoted as their lifetime pregnancy outcome. The most frequent work schedule they worked in is denoted as their lifetime work schedule. Information about their smoking, alcohol, substance abuse and existing comorbid was also obtained. Those respondents with history of self-abortion, medically indicated abortion, with twins, had ectopic pregnancy and part time workers were excluded. Females who had more than three miscarriages were also excluded.

Sample size was calculated based on proportionate sampling from the female population in the healthcare institution. The proportion was based on the Sarawak state crude birth rate which is 16.3 per 1000 population. The healthcare institution had 3023 female healthcare workers. Sample size obtained is 197 pregnancy cases. This sample size was replicated for the comparison group hence 197 pregnancies was obtained from an educational institution.

The healthcare workers were from the only tertiary healthcare centre in Sarawak, Malaysia, which would best represents the working environment for them. The respondents were universally sampled based on a vetted name list according to a set inclusion and exclusion criteria. The number of non-healthcare workers working in the tertiary healthcare centre were too few to produce a statistical analysis hence as a comparison group they were instead obtained from an educational institution about $20 \mathrm{~km}$ away which is representing a different working environment.

Ethical clearance was obtained from the Malaysian Research Ethics Committee which oversees all research conducted in the Ministry of Health and from University Malaysia Sarawak Medical Faculty Ethics Committee that allows research among the community (educational institution).

\section{RESULTS}

The average age (standard deviation) of the respondents is 31.9 (3.4) years. Minimum age is 23 years and maximum are 38 years (maximum age was capped at 38 years following the inclusion exclusion 
criteria). The average age (SD) of pregnancy among all the respondents is 30.2 (3.3) years. The minimum age is 21 and the maximum is 35 years (maximum age was capped at 35 years following the inclusion exclusion criteria). There is a statistically significant difference $(p<0.05)$ in the mean age between healthcare and nonhealthcare workers in respondent age group but not with the age of pregnancy (Table 1).

Majority of healthcare workers are Malays (130) followed by other ethnicities like Bidayuh and Chinese similarly among the non-healthcare workers. Nurses made up the bulk of the healthcare group followed by support staff and doctors. Following the occupation of the respondents the education level of the majority is at diploma level while the rest with degrees and only 23 with Malaysian Exam Certificate. Likewise, the income too follows the majority of the respondents with many of them earning between RM2000 to 5000 . Among the healthcare workers, 266 of them had a single pregnancy reported in the past 3 years and 73 more than two. For the non-healthcare workers 112 had single pregnancy experiences and 18 more than two. (Table 1)

The different work schedule applies to the healthcare workers only in this study. All nonhealthcare workers (130) works office hours only. Hundred and five healthcare workers who responded work office hours, 196 shift and 38 were on-call. The different working schedule between these groups were significant $[\chi 2(\mathrm{df})=0.0001(2), p<0.001)]$. (Table 1)

A total of 564 pregnancies were reported from the 469 respondents. Four hundred and sixteen $(73.8 \%)$ from healthcare workers and 148 (26.2\%) pregnancies among non-healthcare workers. From this, 136 pregnancies had experienced adverse pregnancy events; 113 were among healthcare workers and 23 were among non-healthcare workers. This difference is significant $[\chi 2(\mathrm{df})=0.033(2), p<0.05)]$. Similarly, the lifetime adverse pregnancy outcome of respondents stood at 98 among healthcare workers and 22 among non-healthcare workers and this difference too is significant $[\chi 2(\mathrm{df})=0.008(2), p<0.01)]$.

\section{Table 1: Percentage distribution of respondents among all respondents by sociodemographic characteristics,} pregnancy events and work schedule

\begin{tabular}{|c|c|c|c|}
\hline Characteristics & $\begin{array}{c}\text { Healthcare Staff, } \\
\mathrm{n}(\%)\end{array}$ & $\begin{array}{c}\text { Non-healthcare Staff, } \\
\mathrm{n}(\%)\end{array}$ & $p$ value \\
\hline Number of Pregnancies & $416(73.8)$ & $148(26.2)$ & \\
\hline \multicolumn{4}{|l|}{ Age at pregnancy } \\
\hline $21-28$ & 188 & 55 & \multirow{4}{*}{0.09} \\
\hline $29-35$ & 228 & 93 & \\
\hline Mean, SD years & $30.0,3.4$ & $30.6,3.0$ & \\
\hline Minimum, Maximum & 21,35 & 22,35 & \\
\hline \multicolumn{4}{|l|}{ Lifetime pregnancy outcome } \\
\hline Adverse outcome & 113 & 23 & \multirow{2}{*}{$0.004 *$} \\
\hline Normal delivery & 303 & 125 & \\
\hline Total Respondents & $339(72.3)$ & $130(27.7)$ & \\
\hline \multicolumn{3}{|l|}{ Age of respondents } & \multirow{5}{*}{$0.01 *$} \\
\hline $21-29$ & $99(29.2)$ & $23(17.7)$ & \\
\hline $30-38$ & $240(70.8)$ & $107(82.3)$ & \\
\hline Mean, SD years & $31.7,3.5$ & $32.6,3.2$ & \\
\hline Minimum, Maximum & 23,38 & 24,38 & \\
\hline \multicolumn{4}{|l|}{ Lifetime pregnancy outcome } \\
\hline Adverse outcome & 98 & 22 & \multirow{2}{*}{$0.007 *$} \\
\hline Normal delivery & 241 & 108 & \\
\hline \multicolumn{4}{|l|}{ Race } \\
\hline Malay & $130(38.3)$ & $75(57.7)$ & \\
\hline Bidayuh & $81(23.9)$ & $16(12.3)$ & $0.001 * *$ \\
\hline Chinese & $43(12.7)$ & $15(11.5)$ & \\
\hline Other Races & $85(25.1)$ & $24(18.5)$ & \\
\hline \multicolumn{4}{|l|}{ Occupation } \\
\hline Nurse & $260(76.7)$ & 0 & \\
\hline Doctors & $32(9.4)$ & 0 & $0.001 * *$ \\
\hline Support staff & $47(13.9)$ & 0 & \\
\hline Non-healthcare & 0 & $130(100)$ & \\
\hline
\end{tabular}




\begin{tabular}{|c|c|c|c|}
\hline Education & & & \\
\hline SPM & $23(6.8)$ & $42(32.3)$ & \\
\hline Diploma & $265(78.2)$ & $45(34.6)$ & \\
\hline Degree/ & \multirow{2}{*}{$51(15.0)$} & \multirow{2}{*}{$43(33.1)$} & $0.001 * *$ \\
\hline Postgraduate Degrees & & & \\
\hline \multicolumn{4}{|l|}{ Income } \\
\hline$<2000$ & $21(6.2)$ & $26(20.0)$ & \\
\hline $2000-5000$ & $272(80.2)$ & $91(70.0)$ & $0.001 * *$ \\
\hline$>5000$ & $46(13.6)$ & $13(10.0)$ & \\
\hline \multicolumn{4}{|l|}{ Frequency of Pregnancy } \\
\hline 1 & $266(79.4)$ & $112(86.1)$ & 0.094 \\
\hline$>2$ & $73(20.6)$ & $18(13.9)$ & \\
\hline \multicolumn{4}{|l|}{ Lifetime Work Schedule } \\
\hline Office Hours & $105(31.0)$ & $130(100)$ & \multirow{3}{*}{$<0.0001^{*}$} \\
\hline Shift & $196(57.8)$ & 0 & \\
\hline On-call & $38(11.2)$ & 0 & \\
\hline Adverse Pregnancy Outcome & \multicolumn{2}{|c|}{ Lifetime Pregnancy Outcome, n (\%) } & \\
\hline Hypertensive Disorders in Pregnancy & $16(4.7)$ & $8(6.2)$ & \multirow{7}{*}{$p>0.05$} \\
\hline Complete Miscarriage & $27(8.0)$ & $5(3.9)$ & \\
\hline Threatened Miscarriage & $4(1.2)$ & 0 & \\
\hline Prematurity & $7(2.1)$ & $2(1.5)$ & \\
\hline Low Birth Weight & $22(6.5)$ & $3(2.3)$ & \\
\hline Others & $22(6.5)$ & $4(3.1)$ & \\
\hline None & $241(71.1)$ & $108(83.1)$ & \\
\hline
\end{tabular}

Complete miscarriage is the most commonly reported adverse pregnancy outcome with a total of 32lifetime adverse experienced of pregnancy outcome of respondents were reported. Followed by others at 26, low birth weight at 25 and hypertensive disorders in pregnancy at 24 experiences. Healthcare workers experienced complete miscarriage (35 events) more compared to non-healthcare (five events) workers who experienced more of hypertensive disorders in pregnancy (8 events) (Table 1).

The lifetime work schedule (most common work schedule for those who worked in the past three years) shift/on-call among healthcare workers had 71 (72.3\%) reports of adverse pregnancy outcomes however this difference is not significant. Complete miscarriage also commonly occurred the most among healthcare workers working shift/on-call with 19 reports (Table 2).

Table 2: Percentage distribution of respondents work schedule following lifetime experienced pregnancy outcome among healthcare workers only

\begin{tabular}{|c|c|c|}
\hline \multirow{2}{*}{ Work Schedule of respondents } & \multicolumn{2}{|c|}{ Lifetime Adverse Pregnancy Outcome } \\
\cline { 2 - 3 } & Yes, $\mathrm{n}(\%)$ & No, $\mathrm{n}(\%)$ \\
\hline Office Hour & $27(27.5)$ & $78(32.4)$ \\
Shift/On-call & $71(72.4)$ & $163(67.6)$ \\
Total & $98(100)$ & $241(100)$ \\
\cline { 2 - 3 }
\end{tabular}

Table 3: Percentage distribution of lifetime work schedule following types of lifetime adverse pregnancy outcome among healthcare workers

\begin{tabular}{|c|c|c|c|c|c|c|c|c|}
\hline Work Schedule & $\begin{array}{l}\text { Adverse } \\
\text { Pregnancy } \\
\text { Outcome } \\
\text {-type- }\end{array}$ & 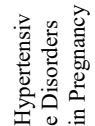 & 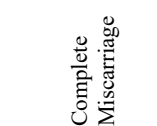 & 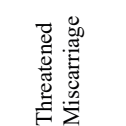 & 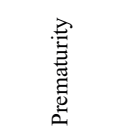 & 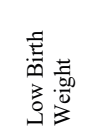 & 竞 & 捲 \\
\hline & Lifetime Ad & Outcome, & & & & & & \\
\hline & & 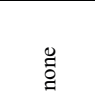 & 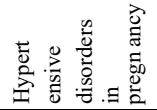 & 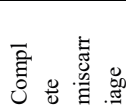 & 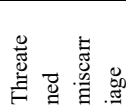 & 芯 & 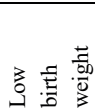 & 竧 \\
\hline \multirow{4}{*}{$\begin{array}{l}\text { Lifetimework } \\
\text { schedule }\end{array}$} & Office Hour & $2(12.5)$ & $7(25.9)$ & $1(25.0)$ & $2(28.6)$ & $6(27.3)$ & $9(40.9)$ & $27(27.5)$ \\
\hline & Shift & $14(87.5)$ & $18(66.7)$ & $2(50.0)$ & $4(57.1)$ & $11(50.0)$ & $13(59.1)$ & $62(63.3)$ \\
\hline & & & & & & & & \\
\hline & On-call & 0 & $2(7.4)$ & $1(25.0)$ & $1(14.3)$ & $5(22.7)$ & 0 & $9(9.2)$ \\
\hline & \multicolumn{8}{|c|}{$p=0.155$} \\
\hline
\end{tabular}


All the respondents denied consuming alcohol, having no history of substance abuse and denied smoking. Eleven healthcare staff reported to have some illnesses such as asthma, thyroid disorders, essential hypertension and others. Six non-healthcare staff reported similar illnesses. Nevertheless, these factors were not confounding.

A multiple logistic regression analysis was carried out to determine which factors mostly influence experiencing of adverse pregnancy outcomes among the respondents. All the statistically significant variables from bivariate analysis were included in the model and entered together. The model contained job category, age, education, race, and income. Results as shown in Table 4 presents the job category and age as the strongest and statistically significant influencer to experience adverse pregnancy outcomes. Healthcare workers have the odds of 2.12 in having adverse pregnancy outcomes than non-healthcare workers. Age group 30 to 38 of the respondents have the odds of 1.71 in having adverse pregnancy outcomes than nonhealthcare workers (Table 4).

Table 4: Multiple logistic regression of lifetime pregnancy outcomes for all respondents

\begin{tabular}{|c|c|c|}
\hline Predictors & $\begin{array}{c}\text { Adjusted } \\
\text { odds } \\
\text { ratio }\end{array}$ & $\begin{array}{c}95 \% \text { CI } \\
\text { Upper limit and } \\
\text { lower limit }\end{array}$ \\
\hline $\begin{array}{c}\text { Job category } \\
\text { Healthcare } \\
\text { Non-healthcare }\end{array}$ & $\begin{array}{c}2.12 \\
1\end{array}$ & $1.26,3.57$ \\
\hline $\begin{array}{c}\text { Age group of respondents } \\
30-38\end{array}$ & 1.71 \\
$21-29$ & 1 & $1.02,2.84$ \\
\hline \multicolumn{2}{|l}{ Adjusted for race, education and income } \\
\hline
\end{tabular}

\section{DISCUSSION}

There are reports whereby $23 \%$ of working women suffered adverse pregnancy outcomes compared to $19.1 \%$ among non-working women. In addition, $76.3 \%$ of healthcare workers, had suffered at least one adverse pregnancy outcome, compared to $55.9 \%$ from nonhealthcare related work (Park et al., 2017). An observational study over a multitude of articles (Mozurkewich et al., 2000) and a study on nurses (Kim et al., 2017) concluded that working hours do influence pregnancy outcomes. Tough inconclusive, the balance of evidence is enough to suggest a possible effect (Ball et al., 2014). Hence the caution on extending the workdays for pregnant women (Harrington, 2001) must be followed. In this study, we have managed to reflect the same occurrences.

From the $12 \%$ prevalence of all pregnancies in United Kingdom ending up with miscarriage (1 in 8), (Bonde et al., 2013), an increase of $1.4 \%$ of cases of miscarriage per 100 pregnancies occur amongst women working shift system (like the practice here). The prolonged night work as well as rotational shifts effect on miscarriage is postulated due the imbalance in reproductive hormones and melatonin following the loss of the biological circadian rhythm (Davis \& Mirick, 2006). Another two case-control studies found an increased risk of spontaneous abortion for shift work and night work (Eskenazi et al., 1994; Xu et al., 2014) A Korean study reports that miscarriages among working women is $17.2 \%$ and among healthcare workers is $18.6 \%$. Among non-working women its only $12.5 \%$ (Park et al., 2017). In Malaysia, there is no data on the prevalence of adverse pregnancy outcomes among females from any work place environment. In this study we managed to prove that there is a 2.12 odds ratio of experiencing an adverse outcome compared to the nonhealthcare workers. Furthermore, the most common adverse pregnancy outcome is miscarriage, similar to the rest of the studies. However, this study could not prove that shift work and on-call work schedule have a significant effect on pregnancy outcome. However, by count, there were more reported cases of adverse outcomes during the shift and on-call work. In addition, miscarriage was the most common.

Two studies had suggested that shift work during pregnancy carries an increased risk of pre-eclampsia (Wergeland \& Strand, 1997; Gabbe et al., 2003). But another study suggested that it did not have any effect (Nurminen, 1989). Most studies did not manage to gather enough cases to come to a significant conclusion (Palmer et al., 2013). However, the mothers who suffered these disorders had psychosocial stress and heavy workload as a risk factor instead. The occurrences of hypertension in pregnancy was more positively related to psychosocial stress (Marcoux et al., 1999; Landsbergis \& Hatch, 1996). Nevertheless, rotational shift work can bring about disturb sleep cycles leading to stress that could lead to adverse pregnancy outcome. In this study the hypertensive disorders of pregnancy were cumulated together, and it showed second highest 
adverse outcome among the healthcare workers and more often occurring among those working shift and oncall. This was however, the highly reported among the non-healthcare workers too. The cumulative stress differs among healthcare and non-healthcare workers hence like literature. There is possible deduction that the adverse pregnancy outcome among healthcare workers are more towards foetal related disorders alone rather than both or exclusive mother related.

According to the Royal College of Physicians, Faculty of Occupational Medicine on average, $6.7 \%$ of pregnant women ( 1 in 15) have a preterm delivery whether or not they work in shifts. This average increases by 0.3 for every 100 births among shift works (Royal College of Physicians n.d.). About 12\% of those working under the Human Health and Social Activities category as reported in a Korean paper had premature delivery (Park et al., 2017) A systemic review paper reports that among the high exposure group generally being women who had worked for at least 40 hours per week in the first two trimesters of pregnancy and those who worked on shifting duties had a higher relative risk from 0.59 to 2.0. With many evidence concurring shifts, such works has a higher relative risk for prematurity. There is also a report which concluded that regular evening or night work may be a risk factor for preterm birth (McDonald et al., 1988). In this study, premature abortion also occurred mostly during shift work although overall it only was $7.1 \%$ of the total adverse cases among healthcare workers. Instead, it was the least reported among non-healthcare workers with only two cases.

Findings on birth weight in relation to working hours on two meta-analysis papers points to limited impact on foetal growth (Palmer et al., 2013; McDonald et al., 1988). However, there is one metaanalysis paper which report the combined risk estimate was 1.27 (95\% CI $0.93-1.74$, test for heterogeneity $p=0.39$ ) for low birth weight (Matteo et al., 2011). One study did a randomized sampling on 1272 pregnant women, found that the longer the working hours during pregnancy increased the risk of low birth weight. Another study on 22761 pregnant women, reported that working hours more than 46 hours per week could lead to low birth weight (McDonald et al., 1988). Working for 51 to 60 hours per week showed a significant relation to low birth weight (Aminian et al., 2014). With refuting claims to the meta-analysis papers, low weight is the third common adverse pregnancy outcome reported in literature. In this study, low birth weight cases occurred mostly during shift work and it is $11.2 \%$ of the total adverse outcomes reported. Only three cases were reported among non-healthcare workers.

This study found that other adverse pregnancy outcomes were high in occurrence. This other adverse pregnancy outcomes mainly include GDM and anaemia in pregnancy. Further study on nutritional intake among pregnant healthcare workers are needed to investigate this risk occurrences.

This study had some limitation in obtaining a larger sample size restricted by the number of pregnant mothers in both the institutions studied. Furthermore, due to the unavailability of readied data of mother's work history from available databases and study time limit constraint, the results cannot be generalised. Nevertheless, the result did reflect the common incidence of adverse pregnancy outcome among healthcare workers and for those working in shifts in accordance with literature. With this study outcome, its replication for further studies may result in exploring the incidence of adverse pregnancy outcomes in different work environments. Since, there is no surveillance or data concerning the relationship between work and pregnancy outcome, it is hopeful that the replication of this study can result with the prevalence also. Other studies (Berkowitz et al., 1990) have recommended having a surveillance for pregnant women as disorders of reproduction is one of the leading work-related diseases and injuries (Yamada, 1986). We also recommend that pregnant mothers to be placed on office hour work schedule and in departments which have less demand for physical involvement duties.

\section{CONCLUSION}

Adverse pregnancy outcomes among female healthcare workers is significantly higher than nonhealthcare workers in this study. Similarly, it has confirmed that with increasing age the risk of experiencing an adverse pregnancy outcome increases.

Shift work reported the greatest number of adverse pregnancy outcome among healthcare workers. There is however no significant difference between adverse pregnancy outcomes and work schedule according to this study among the healthcare workers. 
Complete miscarriage is the most frequently occurring adverse pregnancy outcome followed by low birth weight, hypertensive disorders in pregnancy and other adverse pregnancy outcomes among all respondents. However, among healthcare workers the most common adverse pregnancy outcome is complete miscarriage, followed by low birth weights and others, then hypertensive disorders in pregnancy.

This study however, has only partly concurred with literature's general sentiment whereby healthcare workers do carry a higher risk in developing adverse pregnancy outcome (statistically significant in this study) with shift work, workers being even more susceptible (despite not being statistically significant).
This study however could not proof the statistical significance between the work schedule and adverse pregnancy outcome due to its limitations.

\section{ACKNOWLEDGMENT}

The authors would like to acknowledge the Director General of Health Malaysia for permitting the conduct of this study for publication. We thank the Sarawak State Health Director and the Director of the concerned hospital for permitting the conduct of the study at their institutions. Also the authors would like to thank the Heads of Department of the university concerned. Special thanks to all the respondents for their participation.

\section{REFERENCES}

Aminian, O., Sharifian, S.A.A., Izadi, N., Sadeghniiat, K. \& Rashedi, A. (2014). Association between maternal work activity on birth weight and gestational age. Asian Pacific Journal of Reproduction, 3(3), pp 200-203.

Ball, J., Maben, J., Murrells, T., Day, T. \& Griffiths, P. (2014). 12-hour shifts: prevalence, views and impact. National Nursing Research Unit, King's College London.

Berkowitz, G.S., Skovron, M.L., Lapinski, R.H. \& Berkowitz, R.L. (1990). Delayed childbearing and the outcome of pregnancy. The New England Journal of Medicine, 322(10), pp 659-664.

Bonde, J.P., Jørgensen, K.T., Bonzini, M. \& Palmer, K.T. (2013). Miscarriage and occupational activity: a systematic review and meta-analysis regarding shift work, working hours, lifting, standing, and physical workload. Scandinavian journal of work, environment \& health, 39(4), pp 325-334.

Bonzini, M., Coggon, D. \& Palmer, K.T. (2007). Risk of prematurity, low birthweight and pre-eclampsia in relation to working hours and physical activities: a systematic review. Occupational and Environmental Medicine, 64(4), pp 228-243.

Burdorf, A., Figà-Talamanca, I., Jensen, T.K. \& Thulstrup, A.M. (2006). Effects of occupational exposure on the reproductive system: core evidence and practical implications. Occupational Medicine (Oxford England), 56(8), pp 516-520.

Centre of Disease Control (CDC) (1989). NIOSH: Research and Demonstration Grants, Fiscal Year 1989. U.S. Department of Health and Human Service, Public Health Service, Centers for Disease Control, National Institute for Occupational Safety and Health, Atlanta, Georgis.

Davis, S. \& Mirick, D.K. (2006). Circadian disruption shift work and the risk of cancer: a summary of the evidence and studies in Seattle. Cancer Causes \& Control: CCC, 17(4), pp 539-545.

Eskenazi, B., Fenster, L., Wight, S., English, P., Windham, G.C. \& Swan, S.H. (1994). Physical exertion as a risk factor for spontaneous abortion. Epidemiology (Cambridge, Mass), 5(1), pp 6-13.

Familoni, O. (2008). An overview of stress in medical practice. African Health Sciences, 8(1), pp 6-7.

Figà-Talamanca, I. (2006). Occupational risk factors and reproductive health of women. Occupational Medicine (Oxford England),56(8), pp 521-531. 
Gabbe, S.G., Morgan, M.A., Power, M.L., Schulkin, J. \& Williams, S.B. (2003). Duty hours and pregnancy outcome among residents in obstetrics and gynecology. Obstetrics \& Gynecology, 102 (5 Pt 1), pp 948-951.

Harrington J. (2001). Health effects of shift work and extended hours of work. Occupational and Environmental Medicine, 58(1), pp 68-72.

Kim, O., Ahn, Y., Lee, H-Y., Jang, H.J., Kim, S., Lee, J.E., Jung, H., Cho E., Lim, J.Y., Kim, M.J., Willett, W.C., Chavarro, J.E. \& Park, H.Y. (2017). The Korea Nurses' Health Study: A Prospective Cohort Study. Journal of Women's Health (2002), 26(8), pp 892-899.

Landsbergis, P.A. \& Hatch, M.C. (1996). Psychosocial work stress and pregnancy-induced hypertension. Epidemiology (Cambridge, Mass), 7(4), pp 346-351.

Malaysia Employment Act (1955). Retrieved from: http://www.ilo.org/dyn/natlex/docs/WEBTEXT/48055/ 66265/E55mys01.htm\#c1

Marcoux, S., Bérubé, S., Brisson, C. \& Mondor, M. (1999). Job strain and pregnancy-induced hypertension. Epidemiology (Cambridge, Mass), 10(4), pp 376-382.

Matteo, B., Palmer, K.T., David, C., Michele, C., Antonella, C. \& Ferrario, M.M. (2011). Shift work and pregnancy outcomes: a systematic review with meta-analysis of currently available epidemiological studies. BJOG: $A n$ International Journal of Obstetrics \& Gynaecology, 118(12), pp 1429-1437.

McDonald, A.D., McDonald, J.C., Armstrong, B., Cherry, N.M., Nolin, A.D. \& Robert, D. (1988). Prematurity and work in pregnancy. British Journal of Industrial Medicine, 45(1), pp 56-62.

Mozurkewich, E.L., Luke, B., Avni, M., Wolf, F.M. (2000). Working conditions and adverse pregnancy outcome: a meta-analysis. Obstetrics \& Gynecology, 95(4), pp 623-35.

Nurminen, T. (1989). Shift work, fetal development and course of pregnancy. Scandinavian Journal of Work, Environment \& Health, 15(6), pp 395-403.

Palmer, K.T., Bonzini, M., Harris, E.C., Linaker, C. \& Bonde, J.P. (2013). Work activities and risk of prematurity, low birth weight and pre-eclampsia: an updated review with meta-analysis. Occupational and Environmental Medicine, 70(4), pp 213-222.

Park, C., Kang, M-Y., Kim, D., Park, J., Eom, H. \& Kim, E-A. (2017). Prevalence of abortion and adverse pregnancy outcomes among working women in Korea: A cross-sectional study. PloS One, 12(8), e0182341.

Royal College of Physicians (n.d.). Advising women with a healthy, uncomplicated, singleton pregnancy on: shift work and the risk of miscarriage and preterm delivery. Faculty of Occupational Medicine. Retrieved from: http://www.nhshealthatwork.co.uk/images/library/files/Clinical\%20excellence/Pregnancy_info_shiftwork_ A4.pdf

Wergeland, E. \& Strand, K. (1997). Working conditions and prevalence of pre-eclampsia, Norway 1989. International Journal of Gynecology \& Obstetrics, 58(2), pp 189-196.

Xu, G., Wu, Y., Yang, L., Yuan, L., Guo, H., Zhang, F., Guan, Y. \& Yao, W. (2014). Risk factors for early miscarriage among Chinese: a hospital-based case-control study. Fertility and Sterility, 101(6), pp 1663-1670.

Yamada, S. (1986). [The ten leading work-related diseases and injuries proposed by the National Institute for Occupational Safety and Health(NIOSH)]. Journal of UOEH, 8(4), pp 457-469. 